\title{
Effect of Lactation on Pregnancy Outcomes in Egyptian Women
}

\author{
Elham H. Madny*, and Khaled A. Atwa \\ Department of Obstetrics and Gynecology, Faculty of Medicine, Suez Canal University, Egypt
}

\begin{abstract}
Objective: to evaluate the outcome of pregnancies occurring during the lactation period. $\mathrm{Pa}$ tients and Methods: This retrospective case-control study was conducted among 85 women who had been enrolled after delivery. They were divided into 2 groups according to lactation state at time of conception. Women were compared as regards certain outcomes, including gestational maternal weight gain, abortion, and intrauterine growth restriction, Small for gestational age, intrauterine fetal death and birth weight. Results: Only the incidence of low birth weight was significantly lower among women who got pregnant during lactation (group 1). Mean birth weight was significantly lower among group 1 (3.01 Kg versus $3.4 \mathrm{Kg})$. Odds of birth weight lower than $2.5 \mathrm{Kg}$ increased up to 8 times if pregnancy occurred during lactation. Women in group 1 with obstetric complications continued lactating for longer duration than women of this group with no obstetric complications. Conclusion: There is a significant association between low birth weight and lactation during pregnancy. Duration of lactation during pregnancy has a significant effect on increased incidence of obstetrics complications
\end{abstract}

Keywords: Inter-pregnancy interval, lactation, pregnancy outcome

\section{Introduction}

For many decades, many researchers have studied the relationship between interpregnancy interval and the pregnancy outcomes especially those related to the neonatal outcomes ${ }^{(1)}$. Some of these studies are as early as 1920 s and $1940 \mathrm{~s}^{(1)}$. Various studies have found association rather than causal relationship between short interpregnancy spacing and low birth weight, preterm birth, small for gestational age (SGA), and even perinatal mortality ${ }^{(2-6)}$. Those effects of short inter-pregnancy interval are more obvious among women in developing countries ${ }^{(7)}$ mostly due to the poor baseline nutritional status among these women. Earlier, these associations were roughly attributed to maternal sociodemographic characteristics and lifestyle ${ }^{(8,9)}$. However, the currently available evidence from studies that extensively controlled such risk factors ${ }^{(10-12)}$ suggests that these adverse pregnancy outcomes are not the results of such confounding factors $^{(13)}$. One of the most accepted explanations for this association is maternal depletion and postpartum stress ${ }^{(14)}$. Interpregnancy interval more than 1 year is required to restore the maternal nutritional resources essential for a successful pregnancy $(3,15)$. Maternal nutritional requirement are increased during lactation as well as -and even more than- during 
pregnancy $^{(16)}$. So pregnancy during lactation added to the nutritional requirement, which increases maternal resources replenishment. The aim of the present study was to evaluate the outcomes of pregnancies occurring during the lactation period and to determine potential pregnancy adverse outcomes due to lactation.

\section{Subjects and Methods}

After approval of ethical committee of faculty of medicine Suez Canal University, the present case control retrospective study was conducted among women who had a subsequent pregnancy during the period of lactation. The women were enrolled after giving birth. The study was performed among 85 women presented to outpatient clinic and emergency room of Obstetrics and Gynecology, Suez Canal University Hospital. The study was conducted during the period from January 2011 to December 2011. The enrolled women were divided into two groups according to the cessation of lactation before pregnancy. Group 1 included 53 women who had gotten pregnant while lactating and have stopped lactation before gestational age of 20 weeks. Group 2 included 32 women who had gotten pregnant after cessation of lactation. The medical records of these women were reviewed for pre-gestational body mass index, previous obstetric history including gravidity, parity, previous obstetric complications. Women of both groups were compared as regards pregnancy outcomes, including: preterm labor, abortion, and intrauterine growth restriction, small for gestational age, intrauterine fetal death, and birth weight.

\section{Statistical Analysis}

Microsoft Excel 2003 (Microsoft Corporation NY, USA) and SPSS (Statistical Package for the Social Science; SPSS Inc., Chicago, IL, USA) ver- sion 15 for Microsoft Windows were used to analyze data. Data were statistically described in terms of mean, standard deviation, frequencies, and percentages. For quantitative variables Student $t$ test was used to test the significance of difference and for categorical data Chi square test was performed. P-value $<0.05$ was considered statistically significant. The odds ratio was calculated to measure the estimated risk of adverse outcomes among women who had gotten pregnant while lactating (group 1).

\section{Results}

There was no statistically significant difference between both groups as regard all demographic and previous obstetric characteristics. Mean age was 25.4 and 24.9 years in group 1 and 2 respectively $(p>$ 0.05). Pregestational BMI was $23.57 \mathrm{Kg} / \mathrm{m}^{2}$ in group 1 and $22.86 \mathrm{Kg} / \mathrm{m}^{2}$ in group 2 with no statistically significant difference. There was no significant difference between both groups regarding parity, and history of previous obstetric complications as abortion and preterm labor (Table 1). Incidences of all evidences of adverse outcomes were higher among women of group 1. However, only low birth weight showed a statistically significant difference. Birth weight was higher among women of group 2 compared to women of group 1 (3.4 Kg vs.3.01 Kg). Risk of low birth weight (lower than $2.5 \mathrm{Kg}$ ) increased up to eight times among women of group 1 compared to group 2 . Only $64.2 \%$ of pregnancies in the first group had no complications compared to $90.6 \%$ of pregnancies in the second group in group 1 (Table 2). The Mean duration of lactation during pregnancy was higher among women with complications vs. women without complications among women in group 1 (12.6 \pm 3.5 weeks vs. 10.6 \pm 3.1 weeks; $p<0.05)$. 
Table 1: Baseline characteristics of the studied groups

\begin{tabular}{|l|ccc|}
\hline & $\begin{array}{c}\text { Group 1 } \\
(\mathrm{n}=53)\end{array}$ & $\begin{array}{c}\text { Group 2 } \\
(\mathrm{n}=32)\end{array}$ & $\begin{array}{c}\mathrm{p}- \\
\text { value }\end{array}$ \\
\hline Age & $25.4 \pm 5.3$ & $24.9 \pm 7.2$ & 0.4 \\
$\quad$ Mean \pm SD & $19-28$ & $20-29$ & \\
$\quad$ Range & $11(20.8 \%)$ & $8(25 \%)$ & 0.09 \\
$\begin{array}{l}\text { Parity } \\
\text { NP }\end{array}$ & $36(67.9 \%)$ & $15(46.9 \%)$ & \\
$\quad$ P1 2 & $6(11.3 \%)$ & $9(28.1 \%)$ & \\
$\quad$ P3 & & & 0.6 \\
Pregestational maternal BMI & $23.57 \pm 5.9$ & $22.86 \pm 5.3$ & \\
(Mean \pm SD) & & & \\
Infants sex & $24(45.3 \%$ & $18(56.3 \%)$ & 0.4 \\
$\quad$ Female & $29(54.7 \%)$ & $14(43.7 \%)$ & \\
$\quad$ Male & $2(3.8 \%)$ & $1(3.1 \%)$ & 0.7 \\
Previous abortion & $3(5.7 \%)$ & $1(3.1 \%)$ & 0.9 \\
Previous preterm labor & &
\end{tabular}

$\mathrm{BMI}=$ Body mass index; NS=no statistically significant difference; Group 1=women who had got pregnant while lactating and have stopped lactation before gestational age of 20 weeks. Group 2 women who had gotten pregnant after cessation of lactation

Table 2: Pregnancy outcomes among both groups and estimated risk

\begin{tabular}{|l|cccc|}
\hline & $\begin{array}{c}\text { Group 1 } \\
(\mathrm{n}=53)\end{array}$ & $\begin{array}{c}\text { Group 2 } \\
(\mathrm{n}=32)\end{array}$ & $\begin{array}{c}\mathrm{p}- \\
\text { value }\end{array}$ & $\begin{array}{c}\text { OR } \\
(95 \% \mathrm{Cl})\end{array}$ \\
\hline - Small for gestational age & $3(5.7 \%)$ & $1(3.1 \%)$ & 0.9 & $1.9(0.2-18.7)$ \\
- IUGR & $2(3.8 \%)$ & $1(3.1 \%)$ & 0.7 & $1.2(0.1-13.9)$ \\
- Abortion & $8(15.1 \%)$ & 0 & 0.05 & - \\
- Intrauterine fetal death & $2(3.8 \%)$ & 0 & 0.7 & - \\
- Preterm labor & $4(7.5 \%)$ & $1(3.1 \%)$ & 0.7 & $2.5(0.3-23.7)$ \\
- Birth weight < 2500 g & $11(20.8 \%)$ & $1(3.1 \%)$ & $0.03 *$ & $8.1(0.9-66.2)$ \\
- Birth weight (Kg) & $3.01 \pm 0.8$ & $3.4 \pm 0.7$ & $0.02 *$ & - \\
- No complications & $34(64.2 \%)$ & $29(90.6 \%)$ & $0.01 *$ & $0.2(0.05-0.7)$ \\
\hline
\end{tabular}

IUGR= intrauterine growth restriction, OR: odds ratio; NS=no statistically significant difference; *=statistically significant difference; Group 1 women who had got pregnant while lactating and have stopped lactation before gestational age of 20 weeks; Group 2 women who had got pregnant after cessation of lactation

\section{Discussion}

Although lactation is considered a physiological contraceptive method, pregnancy still occurs during periods of lactation and many women continue to breastfeed their babies during pregnancy for fear of affecting their growth and nutritional require- ments. Nutritional requirements increase during lactation ${ }^{(16)}$ even more than during pregnancy ${ }^{(18-20)}$. Thereafter, the overlap between pregnancy and lactation is considered a great challenge that adds a greater nutritional burden to mothers ${ }^{(21)}$. Interpregnancy interval -or better to be labeled as recuperative interval (duration of the nonpregnant, nonlactating interval)- is 
considered the period to replenish maternal nutritional store. Shortening such period will cause direct effect on nutritional supply available for the new pregnancy $^{(16,21)}$.

The present study has shown that overlap between pregnancy and lactation was associated with increased incidence of many obstetric complications, however only low birth weight showed a statistically significant difference. This finding was consistent with a recent retrospective study, which reported that pregnant lactating women have infants with lower birth weight compared to non-lactating pregnant women ${ }^{(21)}$. We found that duration of pregnancy-lactation overlap was associated with higher risk of poor pregnancy outcomes. As women of first group with complications have duration of lactationpregnancy overlap of 12.6 weeks compared to 10.6 weeks for women of the same group without any complications. Inconsistent with these findings, Sengul and colleagues $^{(21)}$, have shown no association between duration of lactation-pregnancy overlap and poor pregnancy outcome. To the best of our knowledge, most of the previous studies have just evaluated the effects of inter-pregnancy interval on pregnancy outcome without focusing on the effect of lactation. In the present study, we used the inter-pregnancy interval to measure pregnancy spacing, while earlier studies have used birth interval (i.e., the time between two consecutive live births). It has been demonstrated that using birth interval, usually overestimates the adverse effect, especially in the very short birth intervals $^{(1)}$. The assumption that poor pregnancy outcomes with shorter interpregnancy interval and pregnancy lactation overlap is mainly due to the lack in maternal nutritional replenishment, which has been proven by previous researches. van Eijsden and colleagues ${ }^{(13)}$ have found that inter-pregnancy interval was associated with folate depletion that contributes to the increased risk of fetal growth restriction.

\section{Conclusion}

The present study has shown that shorter inter-pregnancy interval and lactationpregnancy overlap is associated with higher incidence of obstetric complications especially lower birth weights. Such finding highlights the importance of health educating the mothers about the importance of adequate inter-pregnancy interval, especially in developing countries such as Egypt, where pre-pregnancy nutritional state has been already inadequate in most of the women. Such adequate period is essential for healthier women and babies.

Limitation of the study:

The main limitation of the current study is a small sample size.

Conflicts of interest:

Authors report no conflict of interest or financial support.

\section{References}

1. Zhu BP. Effect of interpregnancy interval on birth outcomes: findings from three recent US studies. Int J Gynaecol Obstet. 2005: 89 (suppl.1): S25一S33

2. Adams MM, Delaney KM, Stupp PW, McCarthy BJ, Rawlings JS. The relationship of interpregnancy interval to infant birthweight and length of gestation among low-risk women, Georgia. Paediatr Perinat Epidemiol 1997;11(Suppl. 1): 48-62.

3. Klerman LV, Cliver SP, Goldenberg RL. The impact of short interpregnancy intervals on pregnancy outcomes in a low-income population. Am J Public Health 1998; 88 (8):1182-1185.

4. Smith GC, Pell JP, Dobbie R. Interpregnancy interval, and risk of preterm 
birth and neonatal death: retrospective cohort study. BMJ 2003; 327 (7410): 313.

5. Dedecker F, Graesslin O, Ceccaldi PF, Baudelot E, Montilla F, Derniaux E, Gabriel $R$. Short interpregnancy intervals; risk factors and perinatal outcomes. J Gynecol Obstet Biol Reprod 2006; 35 (1): 28-34.

6. Zilberman B. Influence of short interpregnancy interval on pregnancy outcomes. Harefuah 2007; 146 (1): 42-47.

7. Winikoff B. The effects of birth spacing on child and maternal health. Stud Fam Plann. 1983; 14 (10):231-245.

8. Klebanoff MA. Short interpregnancy interval and the risk of low birth weight. Am J Public Health 1988;78 (6):667-670.

9. Klebanoff MA. The interval between pregnancies and the outcome of subsequent births. N Engl J Med 1999;340 (8): 643-644.

10. Zhu BP, Rolfs RT, Nangle BE, Horan JM. Effect of the interval between pregnancies on perinatal outcomes. N Engl J Med 1999;340 (8):589-594.

11. Zhu BP, Haines KM, Le T, McGrath-Miller K, Boulton ML. Effect of the interval between pregnancies on perinatal outcomes among white and black women. Am J Obstet Gynecol 2001;185 (6):1403-1410.

12. Zhu BP, Le T. Effect of interpregnancy interval on infant low birth weight: a retrospective cohort study using the Michigan Maternally Linked Birth Database. Matern Child Health J 2003;7 (3):169-178.

13. van Eijsden M, Smits LJ, van der Wal MF, Bonsel GJ. Association between short interpregnancy intervals and term birth weight: the role of folate depletion. Am J Clin Nutr 2008; 88 (1):147-153.

14. Miller JE. Birth intervals and perinatal health: an investigation of three hypotheses. Fam Plann Perspect. 1991 ;23 (2):6270.

15. Winkvist A, Rasmussen KM, Habicht JP. A new definition of maternal depletion syndrome. Am J Public Health 1992; 82 (5): 691-694.

16. Dewey KG. Impact of breastfeeding on maternal nutritional status. In: Pickering LK, Morrow AL, Ruiz-Palacios GM, Schanler RJ, (eds). Protecting Infants thr- ough Human Milk: Advancing the Scientific Evidence Base. New York: Kluwer Academic/Plenum Publishers; 2004. P.91100.

17. Fleiss JL. Statistical Methods for Rates and Proportions. New York, John Wiley \& Sons, Inc. 1981: 35, 817-819.

18. Institute of Medicine. Dietary Reference Intakes for Thiamin, Riboflavin, Niacin, Vitamin B6, Folate, Vitamin B12, Pantothenic Acid, Biotin, and Choline. National Academy Press: Washington DC; 1998.

19. Institute of Medicine. Dietary Reference Intakes for Vitamin C, Vitamin E, Selenium, and Carotenoids. National Academy Press: Washington DC; 2000: 95-185.

20. Institute of Medicine. Dietary Reference Intakes for Vitamin A, Vitamin K, Arsenic, Boron, Chromium, Copper, Iodine, Iron, Manganese, Molybdenum, Nickel, Silicon, Vanadium, and Zinc. National Academy Press: Washington DC; 2001: 44-59.

21. Sengül Ö, Sivaslioğlu A, Kokanali $M$, Üstüner I, Avşar A. The outcomes of the pregnancies of lactating women. Turk J Med Sci. 2013; 43: 251-254 